\title{
A 24-Hour Lightning Forecast System in Brazil
}

Osmar Pinto Junior¹, Gisele S. Zepka², lara Cardoso¹, Antonio C. V. Saraiva ${ }^{3}$

in dentifying in advance and with reliability favorable atmospheric conditions for lightning occurrence is necessary to minimize injuries and hazardous situations. Different approaches based on empirical and/or statistical methods have been used to forecast lightning occurrence (Shafer and Fuelberg 2008); however, the results in general have serious limitations. In turn, the use of meteorological models with the goal of making forecasts of lightning flash is a recent topic of research that has gained increasing interest in the scientific community. With the advance of the computational capability, the current mesoscale numerical models can run with high-space and time resolutions and explicitly represent individual convective storms and their microphysical properties, although some simplifications are necessary due to the complex electrical processes associated with thunderstorm electrification and lightning initiation (Barthe and Pinty 2007). These processes are still poorly understood.

In particular, lightning forecasting is very important for Brazil due to the large incidence of lightning in the country. Every year Brazil has experienced about 50 millions of ground lightning strikes (Pinto 2009). This number puts Brazil in the top of the list of countries in terms of lightning incidence in the world, followed by the Republic of Congo in Africa and the United States of America. As a result of the large incidence of flashes, on average, 120 people are killed by lightning annually in Brazil. In addition, lightning causes more than one billion dollars in losses every year in the country (Pinto 2009). Brazil is the seventh country in terms of lightning fatalities.

The importance of the forecast system is stressed by the increasing trend of lightning flashes in response to global warming (Hansen et al. 2012) and urban effects that are already observed in large cities of Brazil (Pinto 2009, 2014; Pinto et al. 2013). In part, the increase in the lightning incidence in the future may be related to the increase in the number of severe storms projected by Global Climate Models (GCM). GCM have projected an increase in the extreme climate events (Fischer and Knutti 2014) related to severe storms. In this context, it is quite relevant that the occurrence of severe storms can be monitored by total lightning observations using the new generation of lightning detection networks such as the Brazilian Lightning Detection Network, called BrasilDAT, installed in 2011 (Pinto and Naccarato 2011) by the Atmospheric Electricity Group (ELAT) of the Brazilian Institute of Space Research (INPE), an institution of the Ministry of Science, Technology and Innovation (MCTI). BrasilDAT is a total lightning network detecting and locating both cloud-to-ground and intracloud discharges. The detection of intracloud flashes allow to estimate the severity of a thunderstorm, discriminating severe to non-severe thunderstorms (Lynn et al. 2015).

In order to reduce the lightning fatalities and losses, ELAT announced, in September, 2015, a lightning forecast system, capable to predict the lightning occurrence for the next day for the whole country. The system, developed from the research made by Zepka et al. (2014), is based on the concept of a Potential Lightning Region (PLR), introduced by Zepka (2011), which is a method to calculate the probability of lightning occurrence over a region of interest. It is the first system of this type in Brazil and should be available in the summer season of 2015/2016.

The PLR is calculated using a combination of meteorological variables obtained from high-resolution Weather Research and Forecasting (WRF) model simulations (Zepka et al. 2014). The model parameters used in the PLR definition are a combination of several different parameters including the surface-based Convective Available Potential Energy, instability indices, average vertical velocity at different levels, ice-mixing ratio integrated in an atmospheric layer, among others. The relationship between those parameters with lightning incidence was defined through a series of short-range runs of many non-severe and severe thunderstorm cases with the WRF model, using different convective and microphysical schemes. After a rigorous statistical

1.Instituto Nacional de Pesquisas Espaciais - Grupo de Eletricidade Atmosférica - São José dos Campos/SP - Brazil. 2.Centro Nacional de Monitoramento e Alertas de Desastres Naturais - Cachoeira Paulista/SP - Brazil. 3.Universidade Estadual Paulista "Júlio de Mesquita Filho" - Faculdade de Engenharia de Guaratinguetá Guaratinguetá/SP - Brazil

Author for correspondence: Osmar Pinto Junior | Instituto Nacional de Pesquisas Espaciais - Grupo de Eletricidade Atmosférica | Avenida dos Astronautas, 1.758 Jardim da Granja | CEP: 12.227-010 - São José dos Campos/SP - Brazil | Email: osmar@dge.inpe.br 
evaluation, the best set of parameterizations was chosen as that which best described the convective thunderstorms with lightning in Brazil. After that the forecast system was compared with the lightning observations made by BrasilDAT throughout the summer season of 2014/2015 to evaluate the prediction method. The comparison allows adjusting the method in order to obtain the best level of confidence (approximately 85\%), a value close to what is achieved by the precipitation forecasting in Brazil.

The system output is a color map of the country, with different colors representing different probabilities of lightning occurrence, following the same structure of forecasting prediction maps used by the media. The maps are displayed in a way to make easy the comprehension of the overall audience. This is very important if we want to reduce the lightning fatalities in Brazil. A comprehensive 10-year study about lightning fatalities in Brazil (Cardoso 2011; Cardoso et al. 2014) — with information of the death rates in the country sorted by season, state, city, type of region, age, gender and circumstances, based on data collected from the Federal Civil Defense Agency, the Ministry of Health and the press and including the circumstances of lightning fatalities - indicates that about $80 \%$ of the lightning fatalities in Brazil could be avoided if the population had more information about the lightning risk.

Finally, the forecast system described in this editorial article is part of several activities developed by ELAT in the last decade to provide information about lightning risks in Brazil. Among them, a TV series called "Lightning country" (País dos raios, in Portuguese) and a scientific documentary called "A flash in the tropics" (Fragmentos de paixão, in Portuguese) were produced providing useful information regarding the most important lightning safety rules for the country that can be used in a national lightning safety campaign. All initiatives have the goal of decreasing the number of lightning fatalities.

\section{ACKNOWLEDGEMENTS}

The authors would like to thank the Ministry of Science, Technology and Innovation (MCTI) for supporting the activities described in this editorial article.

\section{REFERENCES}

Barthe C, Pinty JP (2007) Simulation of a supercellular storm using a three-dimensional mesoscale model with an explicit lightning flash scheme. J Geophys Res 112(D6). doi: 10.1029/2006JD007484

Cardoso I (2011) The number of lightning fatalities in Brazil. Scientific American Brazil 110:42-45.

Fischer EM, Knutti R (2014) Detection of spatially aggregated changes in temperature and precipitation extremes. Geophys Res Lett 41:547554. doi: 10.1002/2013GL058499

Hansen J, Sato M, Ruedy R (2012) Perception of climate change. Proc Nat Acad Sci USA 109(37):E2415-E2423. doi: 10.1073/ pnas. 1205276109

Lynn BH, Kelman G, Ellrod G (2015) An evaluation of the efficacy of using observed lightning to improve convective lightning forecasts. Wea Forecasting 30:405-423. doi: 10.1175/ WAF-D-13-00028.1

Pinto Jr O (2009) Lightning in the tropics New York: Nova Publishers.

Pinto Jr O (2014) Thunderstorm climatology of Brazil: ENSO and Tropical Atlantic connections. Intern J Clim 35(6):871-878. doi: $10.1002 /$ joc. 4022

Pinto Jr 0, Naccarato KP (2011) The new Brazilian Lightning Detection
Network: first results. Proceedings of the IX International Symposium on Lightning Protection (SIPDA); Fortaleza, Brazil.

Pinto Jr 0, Pinto IRCA, Ferro MA (2013) A study of the long-term variability of thunderstorm days in southeast Brazil. J Geophys Res 118(11):5231-5246. doi:10.1002/jgrd.50282

Shafer PE, Fuelberg HE (2006) A statistical procedure to forecast warm season lightning over portions of the Florida peninsula. Wea Forecasting 21:851-868. doi: 10.1175/WAF954.1

Shafer PE, Fuelberg HE (2008) A perfect prognosis scheme for forecasting warm season lightning over Florida. Part I: Model development. Mon Weather Rev 136(6):1817-1846. doi: 10.1175/2007MWR2222.1

Takahashi T (1984) Thunderstorm electrification - a numerical study. JAtmosSci41:2541-2558. doi: 10.1175/1520-0469(1984)041<2541: TENS>2.0.CO;2

Zepka GS (2011) Lightning forecasting using Weather Research and Forescasting model (PhD thesis). São José dos Campos: Instituto Nacional de Pesquisas Espaciais.

Zepka GS, Pinto Jr O, Saraiva ACV (2014) Lightning forecasting in southeastern Brazil using the WRF model. Atmos Res 135-136:344362. doi: 10.1016/j.atmosres.2013.01.008 